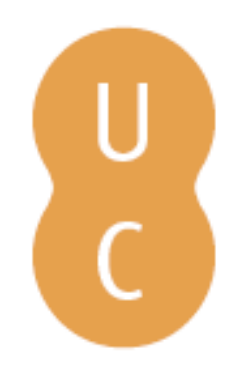

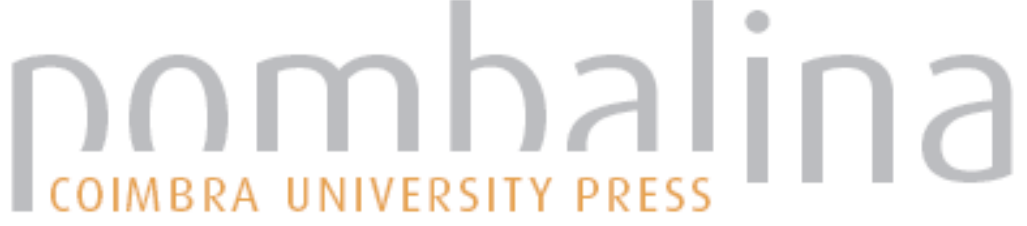

\section{Las biografías de Plutarco como medio de propaganda imperial?}

\author{
Autor(es): $\quad$ Péres Jiménez, Aurelio
}

Publicado por: Imprensa da Universidade de Coimbra

URL

persistente: URI:http://hdl.handle.net/10316.2/32563

DOI: $\quad$ DOI:http://dx.doi.org/10.14195/978-989-26-0442-8_4

Accessed : $\quad$ 26-Apr-2023 08:29:06

A navegação consulta e descarregamento dos títulos inseridos nas Bibliotecas Digitais UC Digitalis, UC Pombalina e UC Impactum, pressupõem a aceitação plena e sem reservas dos Termos e Condições de Uso destas Bibliotecas Digitais, disponíveis em https://digitalis.uc.pt/pt-pt/termos.

Conforme exposto nos referidos Termos e Condições de Uso, o descarregamento de títulos de acesso restrito requer uma licença válida de autorização devendo o utilizador aceder ao(s) documento(s) a partir de um endereço de IP da instituição detentora da supramencionada licença.

Ao utilizador é apenas permitido o descarregamento para uso pessoal, pelo que o emprego do(s) título(s) descarregado(s) para outro fim, designadamente comercial, carece de autorização do respetivo autor ou editor da obra.

Na medida em que todas as obras da UC Digitalis se encontram protegidas pelo Código do Direito de Autor e Direitos Conexos e demais legislação aplicável, toda a cópia, parcial ou total, deste documento, nos casos em que é legalmente admitida, deverá conter ou fazer-se acompanhar por este aviso.

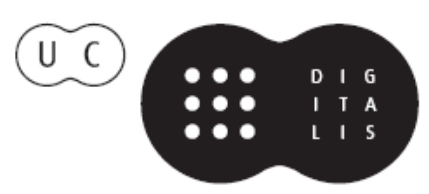


Aurelio Pérez Jiménez, Joșé Ribeiro Ferreira

e Maria do Céu Fialho

(COORdinadores)

\section{Adminiftri Principum.}

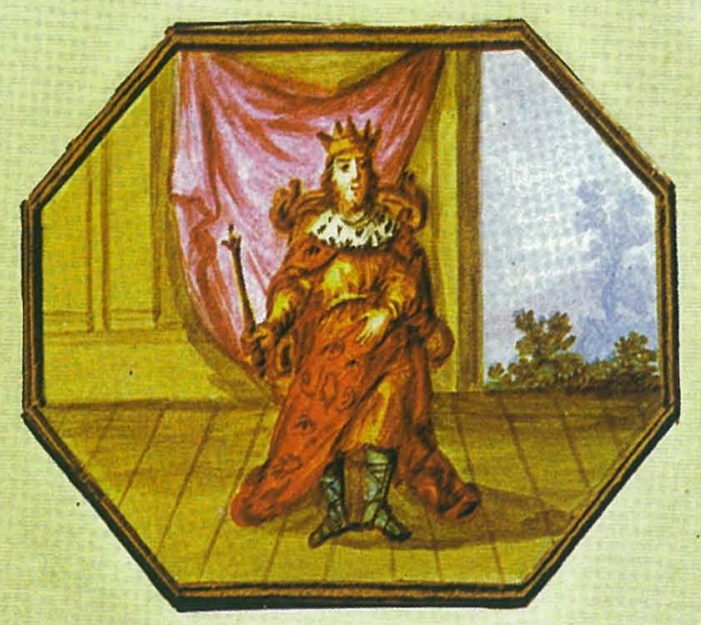

\section{EMBLEM A LIV.}

En tibi plura gerit, quàm lumina prabuit Argos Rex; Aures totidem, quin totidemó, manus. Hec opus Imperio, fidis fupplenda Minijtris, Regi bi funt aures: lumina clara, manus.

\section{- Retrato e a Biografia como estratégia de teorização política}

IMPRENSA DA UNIVERSIDADE DE COIMBRA

Universidad de MálaGa 
(Página deixada propositadamente em branco) 
Aurelio Pérez Jiménez

José RIBEIRo FERREIRA

Maria do Céu Fialho

O RETRATO LITERARIO E A BIOGRAFIA COMO ESTRATÉGIA

\section{DE}

TEORIZACCÃO POLITICA

IMPRENSA DA UNIVERSIDADE DE COIMBRA

UnIVERSIDAD DE MÁlaGa

2004 
Obra publicada com a colaboração de:

Centro de Estudos Clássicos e Humanísticos (Universidade de Coimbra)

International Plutarch Society

Primera edição, Junho de 2004

(c) IMPRENSA DA UnIVERSIDADE DE COIMBRA

(c) Área de Filología Griega. Universidad de Málaga

Coordenação editorial:

Imprensa da Universidade de Coimbra

Área de Filología Griega de la UMA

ISBN: 972-8704-25-9 (PORTUGAL)

ISBN: 84-608-0166-7 (ESPANHA)

Depósito Legal: MA-1420

Impresso em Espanha

Execução gráfica:

IMAGRAF IMPRESORES, S.A.

c/ Nabucco 14

29006 Málaga

Tfno. 952328597

Página de rosto:

"Dos Princepes Transùmptos verdadeiros": Francisco António Novaes Campos, Principe perfeito. Emblemas de D. Joâo de Solórzano. Edição fac-similada do manuscrito da Biblioteca Nacional do Rio de Janeiro oferecido ao Príncipe D. João em 1790 (Prefácio, introdução, comentário e índices por Maria Helena de Teves Costa Ureña Prieto), Instituto de Cultura e Língua Portuguesa, Lisboa, 1985, Emblema LIV, p. 114. 


\title{
¿Las Biografías de Plutarco como Medio de Propaganda Imperial?
}

\author{
Aurelio Pérez Jiménez \\ Universidad de Málaga
}

\begin{abstract}
La publication des Vies parallèles, comme dejà en son temps l'oeuvre de Diodore, Denys d'Halicarnasse et de Strabon, s'adresse à une classe de notables qui commence à n'être plus grecque ni romaine mais habitante de la zone militairement protégée et partageant le même ensemble de valeurs. Certes, ce sentiment unitaire ne touche probablement que la classe qui détient le pouvoir, possède la richesse et produit et consomme la culture, ainsi que les professionnels du commerce ou de la communication. C'est pour cette classe, où qu'elle réside, que Plutarque écrit dorénavant.
\end{abstract}

Jean Serinelli, Plutarque, Paris, 2000, p. 281.

Hace algo más de diez años, en un arrinconado trabajo sobre "El ideal de buen rey según Plutarco", , analizábamos las ideas del Queronense sobre la monarquía, tomando como material de estudio sobre todo los Moralia, aunque proyectando esa imagen teórica a los ejemplos de las Vidas. Al final de ese trabajo apuntábamos la posible relación de estos ideales monárquicos con la historia del Imperio y expresábamos nuestro convencimiento con palabras como éstas:

Qué duda cabe de que muchos de los materiales que el biógrafo selecciona en las Vidas están condicionados por su visión de la corte romana y por las ambiciones, envidias, intrigas, crueldades y mezquindad que genera el poder autoritario del Emperador.

1 En J. M ${ }^{\mathrm{a}}$ Candau Morón, F. Gascó \& A. Ramírez de Verger (eds.), La imagen de la realeza en la Antigüedad, Madrid, 1988, pp. 89-113.

A. Pérez Jiménez, J. Ribeiro Ferreira, Maria do Céu Fialho (edd), $O$ retrato literário e a biografia como estratégia de teorização política, Coimbra-Málaga, 2004, pp. 49-64. 
Ahora la organización de este Seminario sobre $O$ retrato literário e a biografia como estratégia de teorização política me brinda la oportunidad de retomar el tema, allí donde lo dejé entonces y seguir indagando sobre las claves políticas y actuales de una obra tan rica en matices y perspectivas como son las Vidas Paralelas.

Comencemos, pues, con algo que parece evidente: desde el punto de vista de la teoría y la práctica política, Plutarco se encuentra inmerso en una contradicción histórica ${ }^{2}$. Profundo conocedor de la antigüedad griega y romana, entusiasta sobre todo de los valores democráticos de la Atenas clásica y de la Roma republicana, el azar y las circunstancias quisieron que fuera un hombre comprometido con la administración imperial de finales del siglo I y comienzos del II d.C. Aquel amor suyo por el glorioso pasado de Grecia y Roma no parece encajar bien con la tormentosa historia del Imperio de los Claudios y de los Flavios que, después de Augusto, derivó hacia monarquías despóticas de corte tiránico. He aquí la, al menos aparentemente, gran contradicción: Atenas y Roma son los únicos estados de la Antigüedad que se convirtieron en verdaderas potencias cuya influencia, cultural (en el caso de Atenas) y militar, política y económica (en el caso de Roma) era un hecho incuestionable todavía en tiempos de Plutarco. Pero, en ambos casos, fracasaron los gobiernos monárquicos primitivos (con los Pisistrátidas en Atenas y los Tarquinios en Roma), y su triunfo se consumó cuando la soberanía estuvo depositada en el pueblo. Pues bien, para un aristócrata grecorromano, de fluida amistad y comunicación con altos dignatarios de la capital y con los jefes locales de las principales urbes griegas, todos igual que él pertenecientes a familias importantes ${ }^{3}$, en aquella realidad histórica hay algo que no funciona.

La lectura de los poetas y de los historiadores antiguos (tanto atenienses como romanos) podría hacer creer que el mérito de aquellos éxitos (y de algunos fracasos) pertenecía al conjunto de los ciudadanos, que era el fruto de las virtudes y defectos de los respectivos pueblos. Pero un platónico que reclama la lectura directa del fundador de la Academia, prescindiendo de los estadios evolutivos de ésta, al menos tenía algo muy claro: el pueblo, mejor dicho, la chusma (ó $\chi \lambda \circ \varsigma)$ no está capacitada para el ejercicio responsable del poder, que corresponde a los sabios ${ }^{4}$.

2 Que es la contradicción entre un pasado democrático y un presente dominado por la organización imperial, como ha señalado ya antes Domingo Plácido, "La demokratía de Plutarco", en I. Gallo \& B. Scardigli (eds.), Teoria e prassi politica nelle opere di Plutarco, Napoli, 1995, p. 383.

3 Para este tema y la mayoría de los conceptos barajados en este trabajo, sigue siendo indispensable el clásico estudio de C. P. Jones, Plutarch and Rome, Oxford, 1971.

4 Véanse sobre esta hostilidad de Plutarco contra la democracia las oportunas observaciones de J.-C. Carrière, "A propos de la politique de Plutarque", D.H.A., 1977, espec. pp. 
Además, ejemplos como el de Numa en Roma, el de Solón en Atenas y el de Licurgo en Esparta, demostraban que la dicotomía gobierno monárquico = fracaso, y gobierno popular (ya se tratara de democracia al estilo ateniense o de república al modo romano) = éxito, no era tan clara y requería un análisis más complejo.

Por eso, aunque el pretexto para escribir las Vidas Paralelas fuera, como él dice, dibujar con la historia ejemplos de virtud en los que mirarse como en un espejo ${ }^{5}$, Plutarco en realidad busca también otra cosa: se sumerge en ella para tranquilizar, con el análisis individualizado de los hechos, su propia conciencia personal como filósofo, como político y como romano de una clase social elevada; como tal, está cargado de prejuicios, en su mayoría fundados, respecto al grado de responsabilidad política asumible por las clases bajas, que es nula en esa etapa del Imperio ${ }^{6}$. Seguramente por ello - además de por patriotismo local - decidió comenzar la serie con los tebanos, cuya ascensión y declive político en Grecia - cronológicamente bien definido - estuvo muy ligada a la actuación de un hombre sabio: Epaminondas.

No obstante, sería ingenuo creer que Plutarco escribe las Vidas por ese simple prurito intelectual: para, con el análisis de la historia, reafirmar sus ideas platónicas y su mentalidad de clase. Él nunca fue un dilettante, un partidario del ßíos $\theta \epsilon \omega \rho \eta \tau$ เós, ajeno a las corrientes políticas del momento, sino que casi toda su obra tiene una aplicación inmediata a la vida práctica ${ }^{7}$. Sabemos que siempre estuvo comprometido

240-241 y, más reciente, A. Masaracchia, con ejemplos pertinentes de las Vidas y de los Moralia, en su artículo "Sul Plutarco politico", Riv. di Cult. Class. e Med., 1-2 (1994) 540, especialmente pp. 28-34.

5. Nic 1.3-1.4, Alex 1, Aem. 1.2-1.3, Cim. 2.2-2.5.

6 Véase, por ejemplo, el estudio de Z. Yavetz, "The Urban Plebs in the Days of the Flavians, Nerva and Trajan", en Opposition et résistances de l'Empire d'Auguste à Trajan, Entretiens sur l'Antiquité Classique, XXXIII, Vandoeuvres-Genève, 1987, pp. 135-186.

7 Hasta sus convicciones más profundas, como la importancia de la justicia (una virtud que define a la divinidad) o la necesidad de huir de la superstición, encuentran concesiones en el terreno político, cuando se acepta subordinarla al bien común (caso de Aristides, cf. nuestro artículo "Pobreza, Justicia y Patriotismo en la Vida de Aristides de Plutarco", Sodalitas 1 (1980) 147-153) o no se entiende que Bruto la lleve hasta las últimas consecuencias, más allá del amor del padre hacia los hijos (Publ.8.5-6). Un análisis acertado de los principales textos sobre este tema puede leerse en el libro de F. Frazier, Histoire et morale dans les Vies parallèles de Plutarque, Paris, 1996, pp. 158-168. En cuanto a las supersticiones, el propio Plutarco las considera útiles para la gobernabilidad del pueblo en determinadas circunstancias (en este sentido, la prioridad que se concede a las circunstancias políticas a la hora de valorar la conducta de sus personajes, explica algunas contradiciones aparentes dentro de su pensamiento religioso, como hemos demostrado en trabajos anteriores (vid. "La Religión como Instrumento Político en Plutarco", Actas del II Congreso Andaluz de Estudios Clásicos, vol. II, Málaga, 1987, 
con la política y con el destino de sus amigos; y, en las indagaciones históricas de las Vidas, se alegra y sufre sin duda con los éxitos y los fracasos de Grecia y Roma, sin olvidar nunca, con el interés de su compromiso, la historia inmediata del Imperio. De hecho, la situación de su época (con los gobiernos despóticos de los Claudios primero y ahora de Domiciano, tan parecidos a los de los Pisistrátidas y de Tarquinio el Soberbio), de seguir así, no presagiaba nada bueno para el poder constituido.

Pero los tiempos habían cambiado y la solución antigua - sustituir monarquías por gobiernos democráticos - ni siquiera era deseable. La paz de las ciudades se basaba en la estabilidad del Imperio y ésta en la responsabilidad del Emperador y de su administración. Lo demostraban al menos los reinados de Augusto y, recientemente, de Tito. Ahora, tras el régimen de terror impuesto por Domiciano y el difícil equilibrio logrado por Nerva, se ofrecía una oportunidad única de renovación con las virtudes personales, políticas y militares que adornaban a Trajano. Así que, sea o no cierto lo que la leyenda quiere, que el destinatario último de las Vidas Paralelas fuera el mismo Emperador, una cosa es segura: Plutarco contribuye con su análisis personal de la historia antigua al ambiente propagandístico en el que se explican obras como los discursos Sobre la realeza de Dión Crisóstomo y el Panegírico de Plinio el Joven ${ }^{8}$. Las virtudes que nuestro autor exalta y los comportamientos de masas y líderes que comenta en las Vidas son los mismos que contraponen las virtudes del buen rey (Trajano) al tirano (Domiciano) en los años del cambio de siglo ${ }^{9}$. Razones había para ello.

pp. 25-28 y, especialmente, " $\Delta \epsilon \iota \sigma \iota \delta \alpha \iota \mu \nu i ́ \alpha$ ": El Miedo a los Dioses en Plutarco", en Luc van der Stockt (ed.), Plutarchea Lovaniensia. A Miscellany of Essays on Plutarch, Lovaina, 1996, pp. 195-225).

La bibliografía moderna ha analizado en profundidad las relaciones entre estas obras de ambos autores desde J. Morr, Die Lobrede des jüngeren Plinius und die erste Königsrede des Dio von Prusa, Progr. Troppau, 1915. Entre los trabajos más recientes cabe mencionar el de F. Trisoglio, "Le idee politiche di Plinio il Giovane e di Dione Crisostomo", Il Pensiero Politico, 5 (1972) 3-42 (vid. también el apartado dedicado al tema por P. Fedeli en "Il Panegirico di Plinio nella critica moderna", ANRW II 33.1, 1989, pp. 387-514, espec. pp. 433-435).

A. Wardman, Plutarch's Lives, London, 1974, pp. 100-104, es escéptico respecto a la aplicabilidad de las Vidas a la realidad de la Roma de finales del I d.C. en la que no tienen cabida los tres tipos principalmente analizados por Plutarco, el 'político', el 'tirano' y el 'demagogo'. Wardman asume que sólo el tirano podría equipararse al emperador (p. 101: "If anyone were a tyrant it would be the Roman emperor himself") y de ningún modo cabe el 'demagogo'. No obstante, las reflexiones sobre el demagogo en las Vidas Paralelas, como veremos a lo largo de nuestro trabajo, tienen su proyección inmediata para subrayar la irresponsabilidad política de la masa (que convierte a la plebe en un elemento políticamente pasivo en el Imperio) y para exaltar, por contraste, las virtudes 
La desviación política y moral que experimentó el todavía tímidamente democrático régimen de Augusto con sus sucesores está viva en la conciencia histórica de Plutarco. De Tiberio y de Nerón se rechaza su maldad, cuando torturaron y mataron a los amigos de Sejano y de Plauto ${ }^{10}$; a Nerón, además, se le critica indirecta-

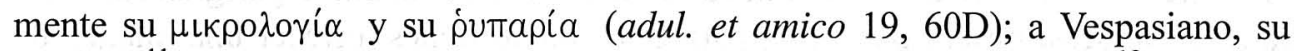
crueldad $^{11} ; \mathrm{y}$, a Domiciano, otros muchos defectos propios de un tirano ${ }^{12}$. Así que, como dijimos, si oficialmente Plutarco fue, o no, preceptor de Trajano, poco importa. Lo que sí creemos es que el trágico fin de la dinastía claudia y flavia, y el comportamiento cruel de algunos miembros de ésta última, pudo condicionar bastante el planteamiento político de las Vidas Paralelas.

De todos modos, con ellas, el sabio de Queronea no se incorpora gratuitamente a la corriente propagandística que envuelve al nuevo régimen de Nerva y Trajano: por una parte, pretende evitar que éste, contaminado por las intrigas de la Corte, pierda sus virtudes castrenses y vuelva a caer en los comportamientos tiránicos de sus predecesores; y, por otra, contribuye a difundir entre sus amigos influyentes de Grecia y Roma las virtudes del nuevo soberano, analizándolas y subrayándolas, al hilo de los materiales a su disposición, en los grandes héroes que, gracias a esas virtudes, hicieron posible la gloria de monarquías, democracias y repúblicas. Las Vidas Paralelas vienen a ser así un instrumento didáctico y propagandístico de primera magnitud, que quizá aportaron su grano de arena a la perduración sin traumas de un nuevo estilo de gobierno ${ }^{13}$.

Hemos dicho que esta posición de Plutarco responde al ambiente general imperante entre la alta sociedad romana de la época de Trajano. Para los filósofos grie-

del 'político', perfectamente aplicables - como también veremos - a la imagen que quiere darse en esa época de los emperadores posteriores a la dinastía flavia.

Amic. mult.7, 96B. Cf. G. J. D. Aalders, Plutarch's Political Thought, Amsterdam, Oxford, New York, 1982, p. 56.

11

Amat. 771C.

Cf. Num. 19.7, Quaest. Rom. 276E, Publ. 15.3-6.

13 Tiene toda la razón A. Masaracchia cuando afirma que "le Vite, nella loro sistematica totalità, non solo rappresentano il frutto più maturo della produzione plutarchea, ma trovano la loro origine e la loro fonte d'ispirazione nelle idee e nei sentimenti dell'epoca di Traiano e della cerchia dell'imperatore" ("Sul Plutarcho politico", cit., p. 14). Por otra parte, nos parece tentadora la idea de que la propaganda que hace de Adriano un Numa (prototipo de religiosidad y pacifismo) pudiera haberse generado en la propia época del Emperador y, tal vez, estar inspirada por la lectura que con toda probabilidad se hacía entonces de la biografía plutarquea del segundo rey romano (cf. sobre esta identificación R. Zoepffel, "Hadrian und Numa", Chiron, 8 (1978) 391-427). 
gos, expulsados por Vespasiano y cuyos amigos fueron víctimas del terror impuesto por Domiciano, la llegada al trono de Nerva y la adopción por éste de Trajano fue un alivio. Aunque sólo sea por la devolución de la libertad a Grecia -cancelada por el primero de los flavios ${ }^{14}$-, el nuevo régimen les permitía albergar grandes esperanzas. No sería difícil, por tanto, para estos intelectuales, ofrecer una imagen de Trajano ajustado al modelo helenístico-romano de buen rey cínico-estoico, que más de una vez se personificó en Alejandro ${ }^{15}$. Ya el mismo Plutarco, en sus tratados retóricos de juventud, se hacía eco de ese ideal, cuya materialización ahora se presenta como posible. Sus palabras, aunque anteriores y, por tanto, desvinculadas todavía de este contexto, podrían haber sido firmadas por los oradores más significados de la propaganda sobre Trajano, Dión Crisóstomo y Plinio el Joven:

Él mismo tenía en sí las grandes esperanzas: la piedad ( $\in$ Ủof́ $\beta \in\llcorner\alpha)$ para con

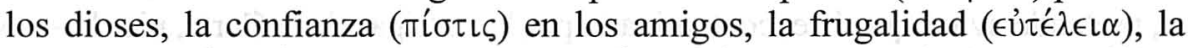

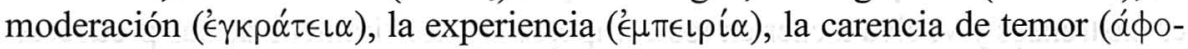
$\left.\beta^{\prime} \alpha\right)$ ante la muerte, el valor ( $\left.\epsilon \dot{u} \psi v \chi \chi^{\prime} \alpha\right)$, la humanidad ( $\phi\llcorner\lambda \alpha \nu \theta \rho \omega \pi i \alpha)$, el trato

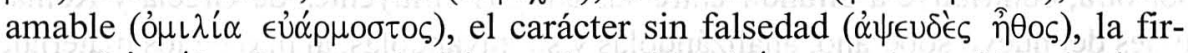
meza $(\epsilon \cup \dot{0} \sigma \tau \dot{\alpha} \theta \in \iota \alpha)$ en sus decisiones, la rapidez ( $\tau \dot{\alpha} \chi 0 \varsigma)$ en la acción, el prima-

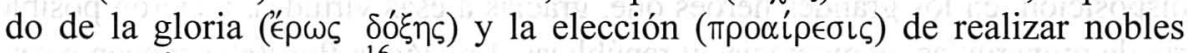
acciones $(\dot{\epsilon} \nu T \tilde{\varphi} \kappa a \lambda \tilde{\varphi})^{16}$.

En efecto, estas y otras virtudes (que atribuye el mismo Plutarco al buen rey en otros tratados), se reúnen en el Panegírico de Plinio y en los $\Pi \epsilon \rho i$ B $\alpha \sigma \iota \lambda \epsilon i \alpha \nu$ de Dión, todos dedicados a Trajano, donde siempre está latente la contraposición con el tirano, representado por Domiciano ${ }^{17}$.

14 Como le echa en cara Apolonio de Tiana: 'A

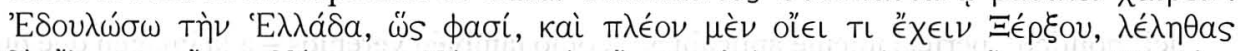

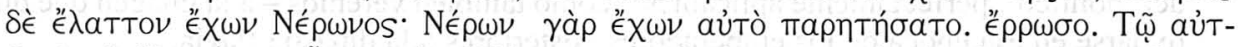

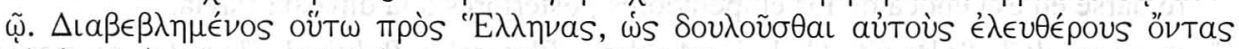

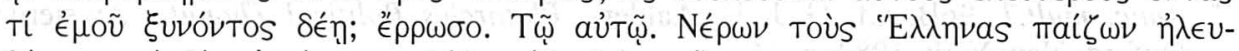

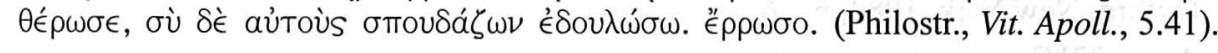

15 A menudo tomando como pretexto el encuentro entre Diógenes y Alejandro, como en Dion.

16 Alex. fort. virt. II 12, 342E-F. Seguimos para el texto la edición de Maria Rubina Cammarota, en el Corpus Plutarchi Moralium, Napoli, 1998.

17 Frente al gobierno ideal, definido por Dión como "cuando una ciudad o varias naciones o el conjunto del género humano están bien gobernados por la sabiduría y la virtud de un solo hombre bueno" (Dio, III45), el tirano es presentado como la explotación violenta y sin ley de los hombres por parte de quien se considera más fuerte (Dio, III44) y, consecuentemente, la tiranía es "cuando un solo hombre, muy perverso, con injusticia y a la fuerza gobierna a otros a los que tiene arruinados." (Dio, III48). Los rasgos del tirano se recogen en Dio, III 116-118. Plin., Paneg. 20.4: "iQué distinto, no hace mucho, el paso de otro príncipe! Si es que se le puede llamar paso y no saqueo, cuando el desahucio 
El emperador lo es por voluntad divina, de cuya providencia forma parte, como $\nu o ́ \mu \circ \varsigma$ " $\mu \psi u \chi \circ \varsigma$. No es elegido por su sangre, sino por su excelencia ${ }^{18} \mathrm{y}$, sobre todo, asume el poder como una obligación, rehusándolo en primera instancia. Plinio dice que es la modestia ${ }^{19}$ de Trajano lo que le impide aceptarlo inmediatamente.

Se exalta su piedad religiosa: tributa a los dioses el culto debido ${ }^{20}$ y cumple con los ritos y consultas oraculares de la tradición ${ }^{21}$. Tiene las virtudes del rey sabio

arrancaba por fuerza el hospedaje, y todo, a diestra y siniestra, quedaba pisoteado e incendiado, como si una calamidad hubiese caído allí, o los mismos bárbaros de que venían huyendo." (trad. A. D’Ors). Cf. 42.4.; 43.5; 48.3. La relación entre el Panegírico y la política de Trajano se analiza con detalle en el artículo de P. Fedeli (ANRW II 33.1, 1989, cit., pp. 461-497, con una excelente discusión de la bibliografía anterior reciente). Véase también, sobre la imagen de Trajano en el Panegírico, P. Soverini, "Impero e imperatori nell'opera di Plinio il Giovane: Aspetti e problemi del rapporto con Domiziano e Traiano", ANRW II33.1, 1989, pp. 515-554, espec. pp. 535-551.

18 Plin., Paneg. 7.4: "No mediaba parentesco de sangre alguno entre el adoptado y el adoptante, ningún vínculo, sino el de ser ambos excelentes, y digno uno de ser elegido y, de elegir, el otro." (trad. A. D'Ors) = Nulla adoptati cum eo qui adoptabat cognatio, nulla necessitudo, nisi quod uterque optimus erat dignusque alter eligi, alter eligere.

19

Paneg. 5.5-7: "Sólo tú no lo querías entender y rehusabas el imperio; lo rehusabas, señal de que ibas a ser un buen emperador. En consecuencia, hubo que forzarte. En realidad, sólo el peligro de la patria y el tambaleo de la república podían hacerlo. Tenías empeño en no asumir el imperio, a no ser por tener que salvarlo. Hasta creo que aquel mismo golpe y movimiento militar sucedió porque sólo con gran violencia y gran terror podía doblegarse tu modestia." = Nec aliter a cunctis omen acceptum est. Nam ipse intelleger nolebas; recusabas enim imperare, recusabas, quod erat bene imperaturi. 6 Igitur cogendus fuisti. Cogi porro non poteras nisi periculo patriae et mutatione rei publicae. Obstinatum enim tibi non suscipere imperium, nisi servandum fuisset. Quare ego illum ipsum furorem motumque castrensem reor extitisse, quia magna vi magnoque terrore modestia tua vincenda erat.

20 Dio, I16: "El buen rey, en primer lugar, es observante de los dioses, tributando honor al culto divino", III 51: "Siendo tal la naturaleza del gobierno, ante todo el rey debe ser un favorecido de la divinidad, como es propio de quien ha obtenido la mayor honra y confianza de parte de los dioses. Y el primer y principalísimo deber consistirá en rendir culto a la divinidad, no solamente confesando su existencia, sino además creyendo sinceramente que los dioses existen, con el fin de que también pueda haber gobernadores que confíen en su dignidad. Ha de estar convencido de que su providencia aprovecha a otros hombres, como el gobierno de los dioses es ventajoso para sí mismo." Plinio legitima en el Panegírico la subida al trono de Trajano como una elección divina (Paneg. 1.4-5; 5.1 y 10.4). Consulta los oráculos, siente un gran respeto por los auspicia. Plinio se refiere a la piedad religiosa de Trajano en Paneg. 52.

21 Las actitudes religiosas de Trajano y de su entorno han sido analizadas con gran rigor en el excelente libro de Santiago Montero, Trajano y la adivinación. Prodigios, oráculos y apocalíptica en el Imperio Romano (98-117 d.C.), Madrid, 2000. Véase también sobre 


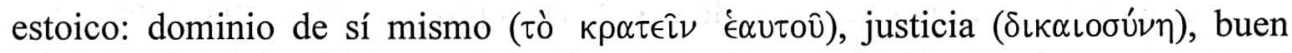

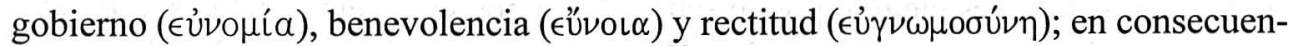

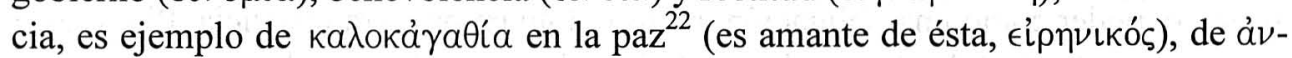

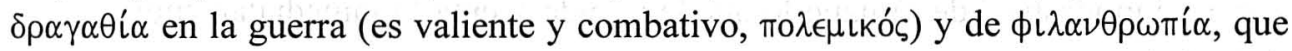
lo acerca a la divinidad. Ante su pueblo exhibe los atributos de los reyes helenísticos: bienhechor ( $\left.\epsilon \dot{U} \in \rho \gamma^{\prime} \epsilon \tau \zeta\right)$ y salvador ( $\left.\sigma \omega \tau \eta \dot{\eta} \rho\right)$. Pero, sin perder la compostura, el

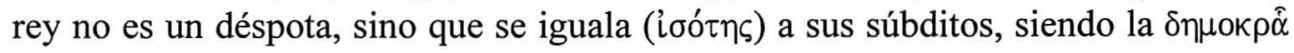
tí $\alpha$ una cualidad del monarca. Se comporta como un padre y entiende como su más sagrado deber el cuidado de los súbditos ${ }^{23}$ : busca siempre el bien de la patria ${ }^{24} \mathrm{y}$, sobre todo, es respetuoso con el Senado ${ }^{25}$ y se somete a las leyes ${ }^{26}$, en lo que contrasta con el déspota Domiciano, que anuló prácticamente el papel de los senadores.

En su comportamiento como gobernante, inspira temor a los enemigos y confianza en sus amigos ${ }^{27}$, en los que, además, confía. Los escoge entre los nobles (los senadores); se complace con la verdad y la sinceridad más que con la adulación y el engaño ${ }^{28}$ y rechaza a los aduladores, como la lacra más vergonzosa para un

este tema el libro de Jean-Pierre Martin, Providentia deorum. Aspects religieux du pouvoir Romain, Roma, 1982, pp. 232-259, con un análisis del Panegírico de Plinio y de las Orationes de Dión de Prusa en pp. 239-248.

22 Dio, I 27: "De tal manera es belicoso que en su poder está el hacer la guerra, y de tal manera pacífico que no deja nada digno de intento por lograr la paz. Porque sabe muy bien esto: que los que están fácilmente preparados para hacer la guerra, éstos tienen en su poder vivir en paz." Plin., Paneg.16.1: "Y tanto más digna de encomio es tu moderación, por cuanto, pese a la gloria bélica en que te criaste, amas la paz" (trad. A. D'Ors) = ... Sed tanto magis praedicanda est moderatio tua quod innutritus bellicis laudibus pacem amas.

Dio, III 55: "Y sobre todo, no ha de considerar el deber de cuidar a sus súbditos como incidental o como trabajo penoso, sintiéndose, pienso yo, abrumado por las preocupaciones, sino que creerá que éste es su cargo y su oficio."

24 Plin., Paneg. 7.1: "No fue tu ambición ni tu miedo lo que te hizo príncipe, sino la utilidad y el temor de los demás." (trad. A. D’Ors) = Non te propria cupiditas, proprius metus, sed aliena utilitas, alienus timor principem fecit.

25

26

Paneg. 62.5.

Idem, 65.

27 Dio, I 25: "A éste los enemigos lo temen y ninguno reconoce ser su enemigo, pero los amigos se llenan de confianza y los que se encuentran cerca de él consideran que se hallan en el lugar más seguro de todos." Cf. III 86ss.

Dio, I 26: "La sencillez y la verdad piensa que son cualidades de un rey y de un hombre prudente, pero la falta de escrúpulos y la astucia las tiene por cosa insensata y servil..." y III 2, probablemente dirigido a Trajano, aunque hay quien piensa en Nerva (p. ej., P. Desideri, Dione di Prusa. Un intellettuale greco nell' impero romano, Firenze, 1978, p. 297, refutado por J. L. Moles, "The addressee of the third kingship oration of Dio Chrysostom", Prometheus, 10 (1984) 65-69). 
gobernante $^{29}$.

En el ámbito privado, a diferencia de otros emperadores, ama a su esposa y lleva una vida sin lujos, ordenada y frugal, entregado al trabajo y no a los placeres y riquezas ${ }^{30}$.

Junto a esta imagen del monarca, es común a todos estos autores una opinión negativa sobre la responsabilidad política del pueblo ${ }^{31}$, que se corresponde con la situación del Imperio. En ese período, las pocas intervenciones políticas que le quedaban al pueblo en el último siglo de la república (elección de magistrados) habían pasado formalmente al Senado con Augusto y sus sucesores. La libertas se identifica ahora con la securitas, a lo que contribuye el bienestar del pueblo en general (repartos de alimentos, cancelación de deudas fiscales y sobre todo un trato considerado) y depende, por tanto, del emperador.

El panorama no es muy distinto al que nos ofrecen los intereses de Plutarco en las Vidas Paralelas, donde son materia de reflexión constante el tirano, el político desinteresado y solícito, preocupado por el bien común, y la incompetencia políti-

Dio, III 17: "Y verdaderamente, nunca la adulación parece que sea respetable ni honorable, aunque uno la practique so pretexto de distinción o por virtud. Porque, por así decirlo, entre todos los vicios uno hallará que la adulación es el más vergonzoso". Plin., Paneg. 41.3: "Pero a tus oídos resulta impedido el acceso, así como de todas las adulaciones en general, muy especialmente de las que inspira la avaricia. 54.1 (refiriéndose a la situación anterior): ¿En qué rincón podía faltar la miserable adulación, ...?” (trad. A. D’Ors)

Dio, I 21: "Además, el buen rey piensa que, por razón de Estado, ha de tener mayor cuidado no de las riquezas y placeres, sino de la administración y de otros servicios. Por ello ha de ser más laborioso que otros muchos, amigos de deleites y riquezas." Plin., Paneg. 7.3: "Has sido asociado al consorcio de trabajos e inquietudes, y no fueron las ventajas y dichas de ese puesto las que te empujaron a tomarlo, sino sus asperezas y dificultades." Plin., Paneg. 41.1-2: "¿Acaso es tan grande el poder de la frugalidad de un príncipe que baste por sí sola para tantos gastos y liberalidades? Assumptus es in laborum curarumque consortium, nec te prospera et laeta stationis istius, sed aspera et dura ad capessendam eam compulerunt; Pues ¿cuál es la causa de que los otros, que arrebataban todo y retenían lo arrebatado, carecieran de todo, como si nada hubieran arrebatado y nada retenido, en tanto tú, a pesar de tantas larguezas y de no quitar nada a nadie, te sobre todo, como si no hicieras largueza alguna, y lo quitaras todo? (trads. A. D'Ors).

31 Véase, p. ej., Dio, III 49, donde define la democracia como "el movimiento variable e impulsivo de la masa, que no conoce absolutamente nada, perturbada y sometida al vaivén de demagogos sin escrúpulos, al igual que una nave en medio de un borrascoso y crudo temporal, llevada de un sitio para otro por la fiereza de los vientos". 
ca del pueblo. Respecto a los tiranos, podríamos pensar que el horror ante ellos (la tiranía es el peor de los regímenes políticos considerados por Plutarco) es fruto del pasado; que sólo refleja aquel miedo ancestral iniciado en la tradición ática con la caída de los pisistrátidas y en la tradición romana con la de los tarquinios, tan largamente alimentado por la teoría y la práctica de los regímenes que siguieron. Pero tenemos datos para creer que la aversión de Plutarco por los tiranos, aunque esté fundamentada en esas tradiciones, se alimenta de la realidad histórica inmediata ${ }^{32}$. Por ejemplo, Nerón es llamado tirano (De garrul. 7, 505C) y probablemente (así lo creen Aalders y otros) también Domiciano en Frat. am. 488A.

Y es que el odio de Plutarco hacia los tiranos no es indiscriminado. No los condena por su nombre, sino por sus hechos y actitudes. Por ejemplo, en la Vida de Solón, aunque se nota una cierta complacencia con la renuncia del sabio ateniense a la tiranía (14.7-8) y con su enfrentamiento a la tiranía de Pisístrato (30), no parece que deje de verla como una solución social en la época arcaica (13.3), con resultados positivos como los de Pítaco y Timondas (14.7) o, parcialmente, el del propio Pisístrato (31.15). En cambio, su actitud se hace visceral con las monarquías despóticas, sumidas en la corrupción y en la degradación moral. En esta categoría entran tiranos y reyes como Amulio, Tarquinio, Dionisio el Viejo y el Joven, Alejandro de Feras (Pelópidas), Nicocles de Sición, Macánidas y Nábide de Lacedemonia (Filopemen), Polícrates (Lisandro), Aristión de Atenas (Sila), Epígono de Colofón (Lúculo), Cinna y Carbón (Pompeyo), Abántidas, Páseas, Nicocles (Arato) y Perseo (Emilio). E incluso reyes ejemplares, como Rómulo, son criticados cuando su monarquía se convierte en depotismo $^{33}$, lo mismo que políticos, como Publícola, cuando, tras la muerte de Bruto, se deja llevar por el boato propio de los tiranos.

Pues bien, la crueldad, la suntuosidad, el aislamiento, el miedo a los amigos, la incontinencia y la vida disoluta de estos personajes recuerdan la conducta de los emperadores y, en concreto, la imagen creada por los partidarios de Nerva y Trajano respecto a Domiciano. La referencia a este último en Publ. 15.5, donde se condena explícitamente el lujo de su palacio, no puede ser más directa ${ }^{34}$ :

32 En este sentido, Vidas como la de Dión o la de Timoleón transfieren a la Antigüedad esquemas propios de la época de Plutarco, como señala L. de Blois: "In his Dion Plutarch sets philosophy against tyranny in an anachronistic way, overaccentuating the role of wise men in classical times as if they were second-century philosophers, who were tutors of emperors and were venerated by earthly princes because of their superior nature and wisdom" ("Political Concepts in Plutarch's Dion and Timoleon", Anc. Soc., 28 (1997) p. 216).

33 Rom. 26.

$34 \mathrm{Su}$ crueldad es objeto de crítica también en Quaest. Rom. 276E. 
Quien admira, en cambio, el lujo del Capitolio, si hubiera visto en la casa de Domiciano un solo pórtico, o una basílica, o un baño o la estancia de las concubinas, es posible que las palabras de Epicarmo al pródigo:

tú no eres caritativo; estás enfermo; te alegras dando

se habría animado a decírselas a Domiciano más o menos en estos términos: tú no eres piadoso, ni amigo de honores; estás enfermo; te alegras construyendo y, como el famoso Midas, quieres que todo se te convierta en oro y mármol.

Contrasta con este alarde en la misma Vida la actitud del cónsul romano que, atendiendo a la franqueza de sus amigos y no a los aduladores (como nos decía Plinio de Trajano), hizo derribar su lujosa casa del Palatino, renunciando a cualquier muestra de despotismo y ganándose por ello el nombre de Publícola.

Naturalmente, en su análisis sobre las causas de la tiranía, Plutarco encuentra la raíz del problema en circunstancias diversas: situaciones de revuelta, pérdida de autoridad de los aristócratas, ambición sin escrúpulos de los políticos y actividad de los demagogos; pero la causa de todo es la ignorancia e irracionalidad del pueblo, que lo deja a merced de sus propias pasiones y de las promesas de satisfacción de éstas formuladas por sus líderes. En el caso de la monarquía romana, el proceso se concreta, además, en la pérdida de su verdadera función por parte del ejército, convertido en simples mercenarios a sueldo del mejor postor, como se indica al comienzo de la Vida de Galba.

\section{4}

Estoy convencido de que la insistente reflexión dedicada a lo largo de las páginas de las Vidas Paralelas a todos esos elementos que conducen inevitablemente a la tiranía, cumple dos funciones dentro de su contexto histórico. Con ello se suma Plutarco a la campaña propagandística de intelectuales como Plinio, Dión de Prusa y, seguramente, Apolonio de Tiana, que incluye no sólo la imagen de Trajano como rey modelo, sino también la damnatio memoriae de Domiciano, como tirano ${ }^{35}$. Pero, además, cumple con su misión didáctica, al ofrecer en los ejemplos de la historia, debidamente comentados, una alerta continua al Emperador y a sus colaboradores sobre el peligro de caer en los mismo errores de los claudios y los flavios.

La actitud de Plutarco respecto al pueblo es la propia de un aristócrata de su tiempo: que éste es ignorante y que su único papel en el Estado es la obediencia a los políticos. Corrompido por los demagogos, busca halagos en vez de hacer lo que se le orde-

El tema ha sido objeto de estudio por parte de S. Levin, "Plutarch's Part in the Damnatio memoriae of the Emperor Domitian", in La Béotie Antique, Lyon-Saint-Étienne, 16-20 mai 1983, Colloques Internationaux du CNRS, Paris, 1985, pp. 283-290. Véase también L. de Blois, art. cit., pp. 214-216. 
$\mathrm{na}^{36}$. Por ello el buen político debe conocerlo y educarlo (coinciden en este punto las Vidas con los planteamientos pedagógicos de los Praecepta), manteniendo ante todo su autoridad y marcando las distancias con aquél, como hizo Pericles. Cuando éstas no están claras, se produce el caos; así ocurrió, por ejemplo, en la Esparta anterior a las reformas de Licurgo, que hizo necesaria la intervención de éste: las claves que propiciaron el regreso de Licurgo fueron su naturaleza hegemónica y su autoridad ${ }^{37}$ (Lyc. 5.1). Pero tan negativo es adular a la chusma por conseguir el poder, al estilo de Alcibíades, como atraerse su odio por intransigencia, como Coriolano (Alc.-Cor. 1.3-4).

Sin embargo, respecto a los órganos que controlan el poder del rey, Plutarco muestra la misma complacencia que Plinio ante el respeto de Trajano a los senadores. En el contexto histórico de que venimos hablando, la explicación sobre el Senado en Rom. 13.3-5 adquiere gran importancia propagandística. La referencia al

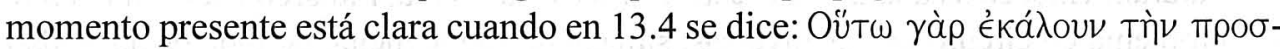

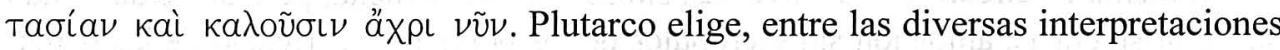
para el nombre 'patricios' dado a los senadores, la que más conviene a sus amigos. Está pensando en su tiempo ( $\mathrm{y}$ tal vez ya aquí se inicie la propaganda que identifica a Trajano con Rómulo ${ }^{38}$, algo que, por otras razones, cuenta con precedentes en la historia de Roma, como los de Camilo y Augusto) cuando se inclina por la que otorga a este organismo una actitud paternalista respecto a los humildes. Por ello Rómulo, "enseñando a los otros a no temer ni mirar con malos ojos las dignidades de los poderosos, sino a tratarlos con agrado, dándoles la consideración y el nombre de padres, así los llamó". Además, en la Vida de Licurgo, su equivalente, la Gerusía, también garantiza la estabilidad, al evitar la oscilación de la monarquía hacia la tiranía o hacia la democracia ${ }^{39}$.

En cuanto a la legitimidad divina del gobernante y al gesto de Trajano, subrayado por Plinio, del rechazo inicial de la corona, tiene sus mejores ejemplos en Numa

36 Thes. 35.4: "en el pueblo grande era la corrupción y el deseo de ser servido en vez de cumplir en silencio las órdenes."

37 Lyc. 5.1: "Los lacedemonios añoraban a Licurgo en su ausencia y, a menudo, le mandaban emisarios, convencidos de que los reyes tenían el nombre y la dignidad del cargo, pero ninguna otra cosa con que se distinguieran del vulgo, mientras que en aquél había cierto natural dotado para el mando y habilidad para guiar a la gente."

Y que cobra forma definitiva más adelante (cf. R. Zoepffel, art. cit., pp. 398-399).

39

Lyc. 5.10: Pues cuando oscilaba el sistema y se inclinaba, bien, como los reyes, hacia la tiranía, o, como la masa, hacia la democracia, colocándose en medio a modo de contrapeso la autoridad de los gerontes y recobrando así el equilibrio, tuvo la más firme organización y estructura, ya que siempre los veintiocho gerontes se unían a los reyes para oponerse a una democracia y, a la inversa, servían de refuerzo al pueblo para evitar la instauración de una tiranía." Cf. D. Plácido, "a.c.", p. 384. 
y Emilio. Respecto a Numa, la versión de Dionisio de Halicarnaso sobre su aceptación de la corona es muy escueta:

Numa, cuando llegaron a su casa los que lo invitaban a aceptar el poder, entonces lo rechazaba y durante mucho tiempo estuvo luchando por no coger la corona; pero ante la insistencia de sus hermanos y, finalmente, como su padre no consideraba justo rechazar ese honor que se le otorgaba, consintió en ser rey ${ }^{40}$.

En Plutarco, en cambio, con la intervención del padre, bastante más elaborada, oímos la voz del encomiasta, sumándose a la propaganda sobre la modestia de Trajano:

Si tú, en particular, ni necesitas dinero, por tu autosuficiencia, ni ambicionas el prestigio < que deriva $>$ de la autoridad y el poder, pues tienes en más estima el que viene de la virtud, sin embargo, juzgando siquiera el ser rey como servicio a un dios que anima y no deja descansar ni permanecer ociosa la justicia que en tan alto grado hay en ti, no huyas ni te apartes del poder, ya que, para un varón sensato, es terreno de bellas y nobles acciones y en él hay magníficas ocasiones, tanto para servir a dioses, como para, encaminándolos hacia la piedad, civilizar a hombres que fácil y rápidamente se dejan cambiar de forma de vida por el que los gobierna (Num. 6.2).

En el caso de Emilio, cuando éste se hace rogar, está dando ejemplo de su desinteresada aceptación del mando único, asumido más como una carga por el bien de la patria, que como objeto de $\phi\llcorner\lambda o \tau \iota \mu i \alpha$. Esto, por otro lado, le deja libres las manos para decidir él (el político sabio) lo que es bueno o malo para el pueblo en momentos críticos. La idea de que la inteligencia (una de las virtudes del rey ideal, contemplada tanto por Plutarco, como por Dión y Plinio) legitima al buen político para ejercer un poder autoritario, cuando las circunstancias lo exigen, sin necesidad de consultar al pueblo, aparece más de una vez en las Vidas. Se hace hincapié en ello no sólo a propósito de Emilio, sino también en el caso de Publícola, que no nombra un colega (para evitar su oposición por envidia o ignorancia) hasta después de las reformas (Publ. 11.1) y en los de Pericles (33.6) y Fabio Máximo (3.6-7). Hasta se considera una ley natural que quien no puede salvarse a sí mismo, se ponga en manos del que puede hacerlo (Pelop. 24.6).

La legitimidad de Trajano, un homo novus y un extranjero de Itálica, encuentra ejemplos en personajes como Temístocles, Teseo, Numa o el propio Cicerón. En la comparación de Lisandro y Sila (Lys.-Syll. 2.3) se dice expresamente que el mérito para gobernar no está en la sangre, sino en la condición del gobernante. En cuanto a sus virtudes, que hemos resumido antes con Plinio y Dión, aparecen a menudo en

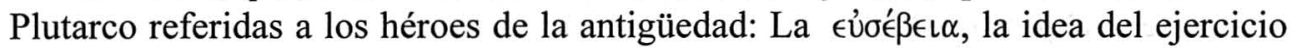


del poder como un servicio, la moderación, la templanza y el respeto a las instituciones, son una constante de análisis por nuestro moralista, como puede verse en el catálogo de Barbara Bucher-Isler. Pero las virtudes más importantes son la modes-

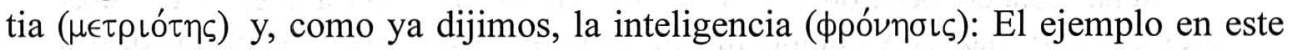

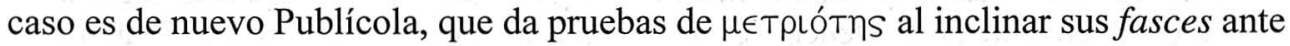
el pueblo, un gesto -comenta Plutarco- con el que no rebaja su autoridad, sino que la refuerza (Publ. 10.8). También Camilo, con la suya, evita la envidia y, con su

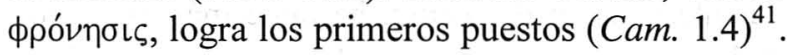

Mas no olvidemos las advertencias del consejero al político: Hay que mantener la autoridad, tensando y aflojando, como hicieron Licurgo y Numa. Y no se puede caer en el despotismo, como Rómulo (Rom. 26), ni en la demagogia como Teseo (Thes.-Rom. 2.2-3) ${ }^{42}$. Pensamos que la reflexión motivada por la evolución de los dos grandes fundadores de la Antigüedad, la actitud de Teseo y de Rómulo está claramente dirigida al Emperador:

Pues el gobernante debe, ante todo, conservar precisamente el mando, y se conserva no menos si es liberado de lo que no conviene, que si se rodea de lo conveniente. Mas el que afloja o tensa, no se mantiene rey ni gobernante, sino que, convertido en demagogo o déspota, infunde el odio o el desprecio en los gobernados ${ }^{43}$.

A menudo reflexiona sobre la degradación moral (fiestas, desenfreno, etc.) de los políticos, que llevan al desastre a sus pueblos y acarrean finalmente su ruina. Otra constante en la teoría política de Plutarco es la defensa de la franqueza y la crítica de la adulación, que tiene sus más logradas páginas en Vidas como la de Alcibíades. Las masacres de enemigos por odio, venganza o intereses más inconfesables (relacionadas, como vimos, con Tiberio y Nerón y recientes en su experiencia de Domiciano) son fuertemente criticadas, como a propósito de las proscripciones de Mario y Sila. Y el desprecio por la religión, en especial la práctica impía de los ritos, produce su indignación, no sólo como sacerdote, sino también por sus consecuencias políticas para el Estado. Es evidente, pues, en la crítica plutarquea de las conductas negativas de sus caudillos, reyes y militares, una referencia inmediata a lo que fue la historia de los emperadores durante todo el siglo I d.C.

Cf. Arist-Cat. Ma. 5.4. También la moderación es típica de la que mira al bien común, mientras que la ambición acarrea dureza, como sucede con Lys.19.2.

42 También Mario fue ejemplo de los peligros que implica la renuncia a la autoridad por favorecer al pueblo (Mar. 28.5).

43

La posible relación de este pasaje con la propaganda de época de Trajano sobre la monarquía justa ha sido señalada por Dión de Prusa (Or. 6.49, contra la monarquía demagógica; cf. p. Desideri, 1978, pp. 297 ss.). Idea tomada de C. Ampolo. 
Resumiendo, si se nos obligara a elegir el personaje plutarqueo que mejor ilustra la imagen de Trajano difundida hacia el año 100, éste podría ser Paulo Emilio: Actúa como un maestro del pueblo y no utiliza los puestos para prepararse otros, sino que se guía siempre por el bien de la comunidad. Como el Emperador, es sumo pontífice y hace demostración en todo momento de la $\in \dot{\sigma} \sigma e ́ \beta \in \operatorname{c} \alpha$. Su actitud hacia lo divino lo lleva a la fidelidad al culto de los dioses, observando las reglas de la tradición. Es celoso en el cumplimiento de los sacrificios expiatorios, como el Trajano ejemplar para los romanos ${ }^{44}$. Así, ante el eclipse previo a la batalla de Pidna, Emilio hace sacrificios a la luna, aunque conoce la teoría científica que explica los eclipses; y lo hace porque es un gesto habitual de piedad ${ }^{45}$. Mantiene siempre las costumbres castrenses y patrias. Cuando la salvación de la patria está en peligro, los romanos acuden a él y ponen a su servicio el mando único, que él rechaza, aceptándolo, como Numa, después de muchos ruegos y exigiendo el uso incondicionado del poder. Actúa con autoridad y franqueza, y se gana de este modo el favor del pueblo. Y de sus intervenciones se desprende el logro de un equilibrio entre las exigencias de la hegemonía romana y el tratamiento liberal a los pueblos sometidos ${ }^{46}$ (¿un desideratum para el Emperador?). Pero, sobre todo, Plutarco admira que Trajano mantuvo su compostura aristocrática y se guió siempre por el parecer de los nobles. Como el Emperador, en suma, el buen político es un instrumento de la providencia divina ${ }^{47}$.

Pero no sólo Emilio. Hay otros personajes que aportan nuevas coincidencias con la imagen pretendida de Trajano. Plutarco no las olvida ni pasa inadvertidamente por ellas, sino que las subraya con sus reflexiones y comentarios. Por ejemplo, de Numa no sólo su religiosidad, su inteligencia, su justicia, su amor por la paz son parangonables a las virtudes de Trajano; sino que aquél, como éste, también fue un extranjero llamado al trono de Roma ${ }^{48}$ que logró conciliar a todos los ciudadanos con sola su ooфía

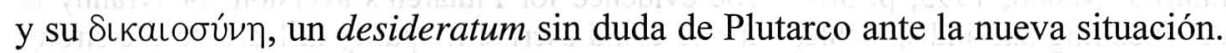

44

Y que, como muy bien señala R. Zoepffel, art. cit., p. 395, llegó a éste, igual que Numa,

Véase sobre esta cuestión S. Montero, o.c., pp. 91 ss.

Cf. también para esta interpretación A. Wardman, o.c., p. 93.

R. Vianoli, "Carattere e tendenza della tradizione su L. Emilio Paolo", in M. Sordi (ed.), Contributi dell'Istituto di storia antica, I, Milano, 1972, p. 87.

En esta línea recordemos las palabras de L. De Blois, "Politics in Plutarch's Roman Lives", $A N R W$, II 33.6, 1992, pp. 4568-4615, p. 4614: "The focus of attention is the moral and ethical quality of the leaders, which should be bounded on an inner law, implanted in them by philosophical paideia and ancestral virtuousness, a nomos empsychos." ya bien maduro. 
En fin, en el análisis plutarqueo de la democracia, ésta se valora positivamente, como dice D. Plácido, cuando "es sociológicamente una oligarquía, que se reparte el poder de manera equilibrada y puede recibir el nombre de aristokratía, y políticamente una basileía, con un poder personal generoso que concede la democracia, representada en sus tiempos en el Imperio romano de la dinastía de los Antoninos" ${ }^{, 49}$. Pues bien, aquí tenemos una nueva clave de por qué, siendo tan negativa la opinión de Plutarco sobre el pueblo, se muestra más hostil a la tiranía que a la democracia radical. A. G. Nikolaidis, siguiendo en parte a Aalders, lo justifica sólo por la tradición antitiránica de las fuentes ${ }^{50}$. Pero no hay que olvidar la perspectiva del momento histórico que vive nuestro biógrafo ni su deseo de influir en él: La democracia radical en la época de Trajano no es ninguna amenaza, mientras que la tiranía, tan reciente todavía la figura de Domiciano, es un peligro que ha de atajarse. Cuando Plutarco carga las tintas sobre el comportamiento de los tiranos, está al mismo tiempo cumpliendo con su misión pedagógica y propagandística como autor de las Vidas Paralelas.

En suma, aparte de la lectura filosófica, histórica y moral, las Vidas Paralelas en relación con los emperadores de Roma son un ejemplo más de la intertextualidad de la obra literaria: En ellas tenemos una aplicación tácita -a veces sugerida por los mismos textos- a la historia real del siglo I d.C. de los prototipos que representan los personajes de la historia antigua ${ }^{51}$. No hemos querido hacer aquí-tampoco era nuestro objetivo- un análisis exhaustivo de sus actitudes y de sus paralelos imperiales, que tal vez sea materia para otro momento; pero creo que con los ejemplos referidos -añádase el tandem Nerón/Antonio/Demetrio, analizado por Brenk ${ }^{52}$ y la posible oposición Emilio-Trajano/ Perseo-Domiciano- creo que es suficiente.

49

50

Esta interpretación nuestra, que pone el énfasis en la proyección de las virtudes heroicas del pasado a la imagen de los nuevos emperadores (Trajano y Adriano) no está reñida con la reivindicación de las estructuras sociales y políticas de la ciudad griega cuya auto-

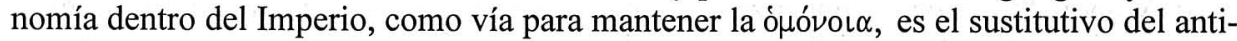
guo ideal de libertad, tal como han señalado otros autores modernos (p. ej., J.-C. Carrière, art. cit., pp. 242-245, F. Frazier en las conclusiones de su libro, pp. 275-281, J. Boulogne, Plutarque, un aristocrate grec sous l'occupation romaine, Lille, $1994 \mathrm{y}$, últimamente, T. Duff, Plutarch's Lives, Oxford-New York, 1999, pp.291-298).

52 33.6, 1992, espec. pp. 4363-4367. 
(Página deixada propositadamente em branco) 


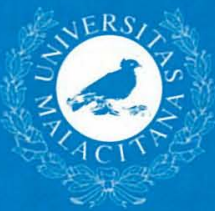

